\title{
Der Mittlere Weg
}

Liebe Leserin, lieber Leser,

Deutschland wird klimaneutral - nicht bis 2050, sondern schon bis 2045. Soweit zumindest der politische Plan. Für die einen scheinen diese Pläne naiv, weil sie das Ziel für nicht erreichbar halten, für andere hingegen, weil es 2045 deutlich zu spät ist, um das Ziel des Weltklimarats von einer maximalen Erderwärmung um $1,5{ }^{\circ} \mathrm{C}$ noch erreichen zu können. Machen wir weiter wie bisher, ist das weltweite Restbudget an zusätzlich freigesetzten, fossilen Treibhausgasen nämlich innerhalb der kommenden sieben Jahre aufgebraucht. Eine Emissionsreduktion kann dieses Budget entlasten, so viel ist klar, aber geschieht das tatsächlich?

Wissenschaftler aus verschiedenen Disziplinen - darunter Prof. Dr.-Ing. Thomas Willner, Verfahrenstechniker an der HAW Hamburg, und Prof. Dr. Thomas Koch vom KIT - weisen in offenen Briefen darauf hin, dass durch den aktuellen politischen Kurs eben keine realen $\mathrm{CO}_{2}$-Reduktionen erfolgen, weil physikalische Wahrheiten durch Rechenmodelle verzerrt werden. Das Problem dabei: Durch die offensichtlichen Schwächen dieser Art der Berechnung wird die eigentlich erforderliche Diskussion, nämlich die über den Klimaschutz, in völlig sinnlose Grabenkämpfe verlagert. Statt ernsthafte Lösungen zu erarbeiten, werden die immer gleichen Stammtischargumente ausgetauscht.

Emissionsreduktionen müssen sofort, überall und nachhaltig erfolgen, um zu einem Erfolg zu führen. Die aktuell gängige Anrechnung mit Emissionsfaktoren und die Nicht-Anrechnung $\mathrm{CO}_{2}$ neutraler Kraftstoffe erfüllen diese Kriterien nicht. Langfristig kann sich sicherlich ein weiterer Wandel vollziehen, Lösungen müssen sich aber in jedem Fall in allen Gesichtspunkten bewähren, um nachhaltig sein zu können. Ein Aufbau einer nachhaltigen Infrastruktur, zum Beispiel in den MENA-Staaten, ist nicht nur umweltfreundlich, sondern bringt auch soziale Vorteile, indem sie regionale Entwicklungen ermöglicht und fördert. Auch wird man wohl kaum Argumente gegen Kraftstoffe aus biologischen Abfällen oder aus Plastikmüll finden, lösen diese doch mehrere Probleme auf einmal. Moderne Verbrennungskraftmaschinen und synthetische Kraftstoffe aus Förderungen auszunehmen, ist in jedem Fall der falsche Weg. Denn zum einen können und werden sie klimaneutral darstellbar sein, und zum anderen sind sie in vielen Einsatzszenarien schlicht alternativlos, nicht nur im Verkehr, sondern in allen Sektoren. Die Elektromobilität zu verteufeln, führt freilich auch nicht zum Ziel. Ein Mittlerer Weg abseits der Extrempositionen sollte doch möglich sein.

Ich wünsche Ihnen viel Spaß bei der Lektüre dieser ATZheavyduty.

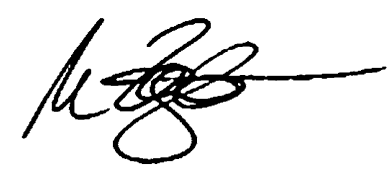

Marc Ziegler

Stellvertretender Chefredakteur MTZ

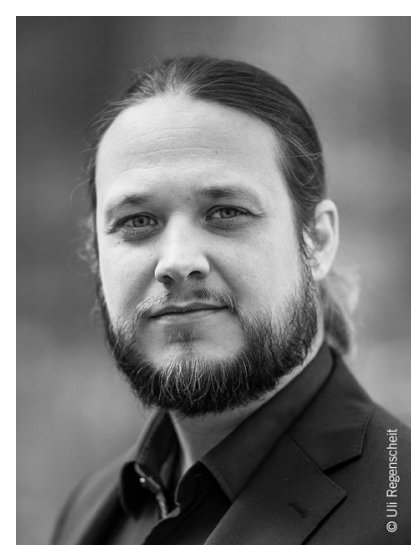

E-T-A Leistungsrelais für Ihre Applikation: Von monostabil bis bistabil und elektromechanisch bis vollelektronisch. Das ideale Schaltelement für innovatives Thermomanagement neuer Abgasreinigungssysteme.

Ihr Nutzen:

- Robust, kompakt und leicht

- Minimaler Energieverbrauch und geringe Erwärmung

- Hohe Performance und lange Lebensdauer

- Keine Korrosion, kein Vereisen der Kontakte dank hermetisch abgedichtetem IP6k9kGehäuse

- Flexible Montagemöglichkeiten inkl. Steckanschluss des Typs HDSCS

- Diagnose- und Timerfunktion

Entdecken Sie unsere Produkte unter www.e-t-a.de

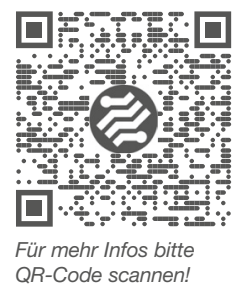

